\title{
The Effect of Assertiveness-Based Sexual Counselling on Sexual Function among Married Female Students
}

\author{
Ameneh Safarzadeh $^{*}{ }^{\mathbb{D}}$, Ali Navidian ${ }^{2}$, Neda Dastyar ${ }^{3}$
}

\begin{abstract}
Objectives: Sexual decency is one of the false beliefs among women about sexual function, and women who have this belief choose an inactive and passive sexual role. The present study aimed to investigate the effect of decisiveness-based sexuality counselling on sexual function among married female students at the University of Sistan and Baluchestan.

Materials and Methods: This quasi-experimental study used a pre-test-post-test design and was conducted on 80 married female students who were selected and randomly assigned to the intervention $(n=40)$ or control $(n=40)$ groups. The data collection tool was Rosen's Sexual Function questionnaire. The intervention group, after the pre-test, took part in four sessions of assertivenessbased sexual counselling weekly across 2 sessions of 90 to 120 minutes. Both groups filled out the questionnaires after the end of the waiting period ( 2 months) (post-test). Chi-square, covariance and independent paired $t$ tests were used to compare the means of the quantitative variables in the 2 groups.

Results: The results showed that the mean score on the sexual function index increased in the intervention group after sexual counselling and decreased in the control group. An independent $t$ test also showed that the difference in mean scores on the sexual function index after sexual counselling in the intervention and control groups was not significant. However, the mean change in the total index score was significantly different in the 2 groups $(P=0.0001)$.

Conclusions: The assertiveness-based sexual counselling method significantly influenced sexual function and expression of sexual rights and reduced the shame and contempt that women in the study felt. It is safe to admit that this method can be used as a way to promote sexuality and to establish a more intimate relationship in marital life.

Keywords: Sexual function, Sexual counselling, Students
\end{abstract}

\section{Introduction}

The word "sexual satisfaction" means a person's pleasant feelings towards sexual intercourse (1) and includes the individual's satisfaction from sexual activity until reaching orgasm (2). According to the World Health Organization (WHO) definition, sexual health is the integration and coordination of the mind, the senses and the individual's body that leads to putting one's social and rational efforts in the direction of personality promotion, and ultimately leads to communication and love among individuals. Therefore, any disorder that leads to the elimination of this coordination and integration results in sexual dysfunction and, as a result, dissatisfaction with sex (3).

The latest theory on sexual function includes 6 components for female sexual function. The sexual desire component is an individual's desire to engage in sexual activity. The sexual arousal component is stimulation of physiological responses in sexual organs, which includes swelling of the vagina, labia and clitoris in women. The slippery or moisture component is vaginal secretions that increase due to arousal and lead to slipping. The orgasm component is characterized by rhythmic contractions of the uterine muscle and external one third of the vagina and anal sphincter. The satisfaction component is the sexual satisfaction from intercourse with the spouse, satisfaction with sexual relations and satisfaction with the whole marital life. The pain component is the amount of vaginal pain during sexual intercourse and postpartum (4).

Various studies have investigated the prevalence of sexual dysfunction. For example, the prevalence of sexual dysfunction in Iranian studies includes Birjand's finding of $60.3 \%$ (5), Yazd's finding of $73.2 \%$ (6), and Sabzevar's finding of $63.21 \%$ (7). In non-Iranian studies, the prevalence of sexual dysfunction is $40 \%$ in the United States and Sweden, 29.6\% in Malaysia and Turkey (8), 69\% in Egypt (9), and 35\% in China (10).

Optimal sexual function and sexual satisfaction results in warmth and passion in couples. It would protect them against many diseases and mental and physical disorders. For example, there is a relationship between sexual satisfaction and reducing heart attacks in men and reducing incidence of migraine headaches, symptoms of premenstrual syndrome and chronic arthritis in women (11). In contrast, people who have 
problems with sexual intercourse usually have low selfconfidence and are also anxious, worried, and depressed (12). Many studies have examined the factors affecting sexual function. Some factors affecting sexual function include age, culture, religion, physical diseases, pregnancy, lifestyle, childhood events, cultural messages, previous generations' experiences, sexual harassment, economic status, communication satisfaction, intimacy, sexual selfdisclosure, non-sexual disclosure and self-esteem $(13,14)$.

Many sexual problems and issues, such as lack of sexual orientation, impotence, and premature ejaculation, are not expressed due to fear and anxiety, shame and embarrassment, or feelings of inefficiency and sin, and these unsolved problems may manifest as other signs and symptoms, such as physical impairment, depression and dissatisfaction with marital life or severe family disputes and even divorce (15).

A number of researchers have argued that sexual problems are not detected in a timely manner due to certain cultural limitations in society, which has led most couples not to seek out counselling centres to resolve their sexual problems and even not to speak about their sexual problems together. However, if these problems can be easily expressed and recognized promptly, there are effective preventive and therapeutic methods for many of them (16).

In such societies, including patriarchal societies, where expressing sexual desire by women can result in insult and men believe that women are sexual objects that do not have sexual desire or sexual assertiveness, women's sexual strife faces negative reactions from men (17). Most people who work in the field of sexual health treatment have found that sexual assertiveness has a very important and decisive role in sexual problems, in identifying the nature of sexual problems, and in examining the growth and development of sexuality (18).

According to some studies, one of the most important factors affecting sexual satisfaction, sexual function and marital satisfaction is sexual assertiveness, or the ability to express sexuality $(19,20)$. Self-efficacy or assertiveness is one of the major variables in Bandura's socio-cognitive theory (21), and it means providing different responses and flexible decisions in unpredictable situations and situations that lead to creating insecurity, hesitation and anxiety in the individual (22). In fact, assertiveness or the ability to express oneself is the behaviour that empowers people to stand up for their beliefs without any fear or anxiety, express their true emotions honestly and establish their rights by taking others' rights into account (23).

There are 2 types of sexual assertiveness. The first type includes the ability to have sex based on one's sexual needs and desires. The second type involves understanding the fact that it is not suitable for anyone to kiss or touch when you do not want someone to touch or kiss you. It is understandable that you do not have to do any sexual activity under pressure with a person with whom you do not feel comfortable (24). In a study by Eunsook and Heesun, it was found that many women in non-gay sexual relations say "no" but in fact mean "yes". Contrary to the sexual revolution taking place in this era, women are still subordinate to men, and the prevailing belief in women is that the man should be preferred in sexual relations. This attitude has led women to not knowingly and freely communicate their sexual, emotional and physical interests to their spouses and ask their spouses to meet their sexual needs, which results in a reduction in sexual assertiveness in women (25).

In our country, the focus of studies on women's health has been on the role of fertility and their offspring. In the area of sexual health, of which sexual satisfaction is one component, few studies have been conducted in this country $(26,27)$. Since marital issues are different in people with higher education and people who lack higher education and statistics indicate an increase in divorce rates in society, students and other groups are not safe from divorce; thus, the present study aimed to investigate the effect of decisiveness-based sexuality counselling on sexual function among married female students at the University of Sistan and Balouchestan.

\section{Materials and Methods}

This quasi-experimental study used a pre-test-post-test design with 80 married female students affiliated with the University of Sistan and Baluchestan. The inclusion criteria were at least one year of marital life; being aged 18 to 40 years; lack of education in psychology or counselling; no history of psychiatric disorders; no use of drugs affecting sexual function; lack of physical illnesses affecting sexual function such as chronic diseases, blood pressure, diabetes or gynaecological surgery; no severe marital conflicts such as the threat of divorce or separation; no infertility; no pregnancy; and not being within three months of delivering a baby. The exclusion criteria were not attending counselling sessions for more than one session; unexpected incidents during the study, such as death or severe physical illness of the person or her family; and pregnancy. The data collection tool was a questionnaire consisting of 2 parts: demographic information, such as the age of the student and her spouse, length of marriage, number of children, type of marriage, having a kinship relationship with the spouse, educational level of the subject and her spouse, employment status of the subject and her spouse, and Rosen's Sexual Function questionnaire, which was designed to assess sexual function in women over the past 4 weeks of the sexual function scale (4) and included 19 sexual items.

The sexual desire section contained 2 sections assessing sexual stimulation and vaginal moisture, each with 4 items, and orgasms, pain and sexual satisfaction, each with 3 items. These sections had a response range of 1 to 5 . In the study by Bahrami et al, the content validity method was used to determine the reliability of this 
questionnaire and validated the tool (27). The reliability of the tool was determined by calculating Cronbach's alpha coefficient, which was $87 \%$. In addition, to assess test-re-test reliability, Spearman correlation coefficient (93\%) and the $P$ value $(P)$ were $31 \%$ from the pre-test and post-test. There was no significant difference between the results of the 2-time completion of the questionnaire; and the stability of the questionnaire was confirmed (27). The sexual function index was standardized in Iran by Fakhri et al, having good validity and reliability (28). In this study, the reliability of this tool was also measured by Cronbach $\alpha$. The research units were divided into the intervention and control groups with the convenience sampling method. First, demographic information and sexual function questionnaires were completed as a pretest for all control groups. Then, the control group filled out the questionnaires after the end of the waiting period (2 months) (post-test). The intervention group, after the pre-test, took part in four sessions of assertivenessbased sexual counselling weekly for 2 sessions of 90 to 120 minutes. The content of the therapeutic sessions was provided according to the table using educational tools, including a whiteboard, slideshow, and question and answer sessions, and some assignments related to the previous session were given to the participants. After completing the sessions, they were invited by telephone call to come to the counselling center for a post-test after 2 months (Table 1).

Data Analysis and Description

Following data collection, data were analyzed with SPSS software version 20.0. Descriptive statistics (frequency distribution, mean, standard deviation, and percentage) were used to describe the data. To examine the qualitative variables in the 2 groups, chi-square tests were used. To examine the means of quantitative variables in the 2 groups, independent t-tests were used. To examine the means of quantitative variables before and after the intervention, paired $t$ tests were used, and the covariance test was used to examine the effect of the intervention and control the pre-test effect.

\section{Results}

The distributions of some of the demographic variables in the control and intervention groups are summarized in Table 2. The results of independent t-tests showed that there was no significant difference between the 2 groups in demographic variables $(P \geq 0.05)$ (Table 2$)$.

Comparisons of different dimensions of the sexual function index are presented in Table 3. For the sexual desire dimension, the results showed that the mean score of sexual desire in the intervention group increased after sexual counselling. Independent $t$ tests did not show a significant difference in the mean score of sexual desire in the control and intervention groups after sexual counselling $(P=0.09)$, but the mean changes in the 2 groups were significant $(P=0.0001)$. The results showed that the mean post-test sexuality scores in the intervention group increased after sexual counselling, and the scores fell in the control group. Independent t-tests showed that there was no significant difference between the mean score of sexual arousal after sexual counselling in both the intervention and control groups $(P=0.09)$. However, the mean score changes in the 2 groups were significant $(P=0.001)$. According to the results, the vaginal moisture dimension of the sexual function index decreased in the intervention group after sexual counselling and also slightly changed in the control group. An independent t-test showed that the mean score for vaginal moisture after sexual counselling in both the intervention and control groups was not significantly different $(P=0.22)$. There was no significant difference in mean score changes in the 2 groups $(P=0.09)$.

The scores on the orgasm dimension in the intervention group before sexual consultation were increased, and increased again after sexual consultation. Independent t-tests showed that the mean scores on the orgasm dimension after sexual counselling in both the intervention and control groups were not significant $(P=0.11)$. However, mean score changes in the 2 groups were significant $(P=0.001)$.

According to Table 3 , the scores on the sexual satisfaction dimension of the sexual function index in the

Table 1. The Timetable and Content of the Assertiveness-Based Sexual Counselling Sessions

\begin{tabular}{ll}
\hline Session & Content \\
\hline Session 1 & $\begin{array}{l}\text { Introductions and familiarity of the members with each other, initial communication, familiarity with the principles and objectives } \\
\text { of the session, internal and external genital anatomy of women and men, genital physiology, principles of communication and } \\
\text { sex, sexual function, and normal sexual response cycle }\end{array}$ \\
Session 2 & $\begin{array}{l}\text { Education on assertiveness in communication, the need for self-expression and its benefits in life, the right to express, or not, the } \\
\text { right to freedom of choice, homework and feedback. }\end{array}$ \\
Session 3 & $\begin{array}{l}\text { Reviewing previous session assignments, teaching different types of behaviour, identifying assertive behaviour and non-assertive } \\
\text { behaviour (passive and aggressive), the skill of saying no, discussing saying "yes" and "no", the reasons for not being able to say } \\
\text { yes and no, giving homework and receiving feedback }\end{array}$ \\
& $\begin{array}{l}\text { Reviewing previous session assignments, defining sexual assertiveness, expressing the benefits of sexual assertiveness, and } \\
\text { factors influencing increasing sexual assertiveness, providing solutions to increase sexual assertiveness, question and answer, } \\
\text { and summing up. }\end{array}$ \\
\hline
\end{tabular}


Table 2. Distribution of Some Demographic Variables

\begin{tabular}{|c|c|c|c|}
\hline Variable & $\begin{array}{l}\text { Intervention } \\
\text { Group }\end{array}$ & $\begin{array}{l}\text { Control } \\
\text { Group }\end{array}$ & $\boldsymbol{P}$ \\
\hline Age (mean and SD) & $22.30 \pm 2.81$ & $22.47 \pm 3.10$ & 0.79 \\
\hline $\begin{array}{l}\text { Spouse's age (mean and } \\
\text { SD) }\end{array}$ & $26.58 \pm 3.37$ & $26.67 \pm 3.69$ & 0.89 \\
\hline Duration of marriage & $3 \pm 2.21$ & $3.35 \pm 2.23$ & 0.61 \\
\hline Number of children & $0.35 \pm 0.53$ & $0.60 \pm 0.74$ & 0.08 \\
\hline Education & & & 1 \\
\hline Bachelors & $33(82.5)$ & $34(85)$ & \\
\hline Masters & $7(17.5)$ & $6(15)$ & \\
\hline Total & $40(100)$ & $40(100)$ & \\
\hline $\begin{array}{l}\text { Having relationship before } \\
\text { marriage }\end{array}$ & & & 1 \\
\hline Yes & $27(67.5)$ & $28(70)$ & \\
\hline No & $13(32.5)$ & $12(30)$ & \\
\hline Total & $40(100)$ & $40(100)$ & \\
\hline The type of marriage & & & 1 \\
\hline Voluntary & $30(75)$ & $35(87.5)$ & \\
\hline Forced & $10(25)$ & $5(12.5)$ & \\
\hline Occupation & & & 1 \\
\hline Employee & $40(100)$ & $39(97.5)$ & \\
\hline Unemployed & 0 & $1(2.5)$ & \\
\hline Total & $40(100)$ & $40(100)$ & \\
\hline
\end{tabular}

intervention group were low before sexual counselling but increased after the intervention. The mean score changes in the 2 groups were significant $(P=0.001)$. The sexual pain dimension decreased in the intervention group after sexual counselling but increased in the control group. Independent $t$ tests showed that the mean sexual pain score after sexual counselling in both the intervention and control groups was not significantly different $(P=0.65)$. However, the mean score changes in the 2 groups were significant $(P=0.001)$.

The results of our study showed that the mean score on the sexual function index increased in the intervention group after sexual counselling and decreased in the control group. Independent $t$ tests also showed that the mean scores on the sexual function index after sexual counselling in the intervention and control groups were not significant $(P=0.13)$. However, the mean change in the total index score was significant in both groups $(P=0.001)$ (Table 4).

Based on the results of Kolmogorov-Smirnov tests (Statistic, 0.98 and $P=0.33$ ) and Levene tests $(F=0.87$, $P=0.35)$ of the assumptions of approximate normality and homogeneity of variance, the necessary conditions for using the covariance analysis test were met. The results of the analysis of covariance test controlling for pre-test scores showed that the mean score on the total sexual function index in the 2 groups after intervention was statistically significant $(P=0.001)$, which means that sexual counselling in the intervention group increased the mean score of the students' total sexual function index (Table 5).

\section{Discussion}

The results of our study showed that assertiveness-based sexual counselling increased the mean total score on the sexual function index in married students. These results are consistent with findings by Hargie and Dickson (22). Hargie and Dickson's results showed that education on assertiveness skills could improve interpersonal relationships in the intervention group. In a study by Bay et al in Iran, which was carried out in order to examine the role of sexual assertiveness and sexual orientation in predicting female sexual function, there was a significant correlation between female sexual assertiveness, selfawareness and sexual function, and women with higher sexual assertiveness had better sexual union (24). The results of a study by Vaziri et al, which examined the effect of sexual assertiveness on marital satisfaction, showed that sexual assertiveness can predict marital satisfaction scores (29). Based on the available scientific evidence, it can be argued that the main variable in improving female sexual function is self-awareness and sexual assertiveness, which is similar to our results (30). Since the Sexual Function Questionnaire used in this study (FSFI questionnaire) consisted of 6 sections (sexual desire, sexual arousal, vaginal moisture, orgasm, sexual satisfaction, and sexual pain), paired $t$ tests showed that the average postintervention score changes of all components, except for the vaginal moisture dimension, were significant. It was similar to the results of the Vural and Temel's study, which were based on the IMB (Information, Motivation, Behavioural) counselling method (31).

Concerning the lack of significance on the vaginal moisture dimension, it may be possible to say that in assertiveness-based counselling sessions, the issue of flirting before intercourse should be emphasized because it can cause more vaginal secretions of the Bartholin gland during sexual intercourse. In our country's culture, many men do not pay much attention to sexual arousal resulting from non-genital stimulation (sexual stimulation of the partner, breast stimulation, kissing, and stimulating sensitive points on the partner's body) before sexual intercourse, and they directly engage in sexual intercourse. In either case, considering the significance of the total score on the sexual function index in the intervention group compared to the control group, apparently, it cannot be said that a lack of emphasis on this issue has caused sexual dysfunction and women's sexual satisfaction in our study.

On the orgasm dimension, our study showed that this dimension of the sexual function index in the intervention group was significantly different from the control group, which is consistent with findings by Ayaz and Kubilay 
Table 3. Comparison of Mean and Standard Deviation of Various Dimensions of Sexual Function Index and Changes Before and After SexualAssertiveness Consultation in Both Groups

\begin{tabular}{|c|c|c|c|c|}
\hline Variables & $\begin{array}{c}\text { Before intervention } \\
\text { Mean } \pm \text { SD }\end{array}$ & $\begin{array}{c}\text { After intervention } \\
\text { Mean } \pm \text { SD }\end{array}$ & $\begin{array}{c}\text { Changes } \\
\text { Mean } \pm \text { SD }\end{array}$ & $t$ test \\
\hline $\begin{array}{l}\text { Sexual desire } \\
\text { Intervention } \\
\text { Control } \\
\text { Pair-wise t-test }\end{array}$ & $\begin{array}{c}3.48 \pm 1.12 \\
3.84 \pm 1.04 \\
0.14\end{array}$ & $\begin{array}{c}3.96 \pm 0.77 \\
3.61 \pm 1.03 \\
0.09\end{array}$ & $\begin{array}{c}0.48 \pm 0.82 \\
-0.22 \pm 0.50 \\
0.0001\end{array}$ & $\begin{array}{l}0.001 \\
0.007\end{array}$ \\
\hline $\begin{array}{l}\text { Sexual arousal } \\
\text { Intervention } \\
\text { Control } \\
\text { Pair-wise t-test }\end{array}$ & $\begin{array}{c}3.54 \pm 1.12 \\
4.17 \pm 1.04 \\
0.01\end{array}$ & $\begin{array}{c}4.32 \pm 0.71 \\
3.81 \pm 0.92 \\
0.008\end{array}$ & $\begin{array}{c}0.8 \pm 0.77 \\
-0.36 \pm 0.44 \\
0.0001\end{array}$ & $\begin{array}{l}0.0001 \\
0.0001\end{array}$ \\
\hline $\begin{array}{c}\text { Vaginal slippery } \\
\text { Intervention } \\
\text { Control } \\
\text { Pair-wise t-test }\end{array}$ & $\begin{array}{c}3.17 \pm 0.65 \\
3.10 \pm 0.52 \\
0.61\end{array}$ & $\begin{array}{c}2.98 \pm 0.46 \\
3.10 \pm 0.41 \\
0.22\end{array}$ & $\begin{array}{c}-0.18 \pm 0.54 \\
0.0 \pm 0.45 \\
0.09\end{array}$ & $\begin{array}{l}0.03 \\
0.99\end{array}$ \\
\hline $\begin{array}{c}\text { Orgasm } \\
\text { Intervention } \\
\text { Control } \\
\text { Pair-wise t-test }\end{array}$ & $\begin{array}{c}3.66 \pm 0.76 \\
3.93 \pm 0.62 \\
0.08\end{array}$ & $\begin{array}{c}4.02 \pm 0.57 \\
3.80 \pm 0.67 \\
0.11\end{array}$ & $\begin{array}{c}0.36 \pm 0.55 \\
-0.13 \pm 0.37 \\
0.0001\end{array}$ & $\begin{array}{c}0.0001 \\
0.03\end{array}$ \\
\hline $\begin{array}{l}\text { Sexual satisfaction } \\
\text { Intervention } \\
\text { Control } \\
\text { Pair-wise t-test }\end{array}$ & $\begin{array}{c}4.15 \pm 1.33 \\
5.00 \pm 1.07 \\
0.002\end{array}$ & $\begin{array}{c}4.75 \pm 0.82 \\
4.65 \pm 1.12 \\
0.65\end{array}$ & $\begin{array}{c}0.60 \pm 0.91 \\
-0.35 \pm 0.43 \\
0.0001\end{array}$ & $\begin{array}{l}0.0001 \\
0.0001\end{array}$ \\
\hline $\begin{array}{c}\text { Sexual pain } \\
\text { Intervention } \\
\text { Control } \\
\text { Pair-wise t-test } \\
\end{array}$ & $\begin{array}{c}3.45 \pm 1.32 \\
2.50 \pm 1.09 \\
0.001 \\
\end{array}$ & $\begin{array}{c}2.79 \pm 0.97 \\
2.88 \pm 0.92 \\
0.65 \\
\end{array}$ & $\begin{array}{c}-0.66 \pm 0.81 \\
0.38 \pm 0.59 \\
0.0001 \\
\end{array}$ & $\begin{array}{l}0.0001 \\
0.0001\end{array}$ \\
\hline
\end{tabular}

from studies that examined sexual function based on the PLISSIT and Enhancing Marital Sexuality (EMS) models (32). However, it is not consistent with Vural and Temel's study that indicated the change in orgasm was not significant in the intervention group (31). Perhaps one of the reasons for this difference can be found in the mirage duration factor, because in the study by Vural and Temel, subjects were those who were newly married, but in our study, the average marriage duration was 3 years in the intervention group and 3.35 years in the control group. In other words, greater experience with marital life in reaching orgasm can be considered a difference with the study by Vural and Temel. Another reason could be cultural differences because their study was carried out in Turkey. The third reason for this difference could be the counselling method.

In a study by Kiefer and Sanchez, the results showed that women who have more orgasms have greater ability to express their sexual needs and desires, and these women are able to start sexual activity and direct it to be what they want $(33,34)$. Compared to women with fewer orgasms, they not only do not have this ability, but they are also more likely to emphasize the sexual satisfaction of their partner. Alternatively, some studies have shown that there is a strong relationship between oestradiol and testosterone in women and increased sexual function in couples. Gonadal steroids in both sexes can lead to more sexual assertiveness and better orgasms, which would lead to increased sexual pleasure in couples. This issue doubles the importance of sexual assertiveness in promoting marital relationships, especially the important dimension of orgasms in women $(35,36)$.

In our study, the mean scores on the sexual satisfaction dimension after the intervention were significantly increased compared with the control group, which was consistent with the study by Pakgohar et al carried out in

Table 4. Comparison of the Mean and Standard Deviation of the Total Sexual Function Index and Changes Before and After the Assertiveness Sexual Counseling in Both Groups

\begin{tabular}{lccc}
\hline \multirow{2}{*}{ Group } & \multicolumn{2}{c}{ Time } & Changes \\
\cline { 2 - 4 } & $\begin{array}{c}\text { Before Intervention } \\
\text { Mean } \pm \text { SD }\end{array}$ & $\begin{array}{c}\text { After Intervention } \\
\text { Mean } \pm \text { SD }\end{array}$ & Mean \pm SD \\
\hline Intervention & $21.45 \pm 3.81$ & $22.82 \pm 2.32$ & $1.37 \pm 2.56$ \\
Control & $22.52 \pm 2.98$ & $21.86 \pm 3.22$ & $-0.68 \pm 1.22$ \\
Independent $t$ test & 0.26 & 0.13 & 0.0001 \\
\hline
\end{tabular}


Table 5. Results of Covariance Analysis Related to Total Score of Sexual Function Index After Counseling With Control of Pre-test Effect

\begin{tabular}{llllllll}
\hline Source of Changes & Sum of Squares & $d f$ & Mean of Squares & $\boldsymbol{F}$ & $\boldsymbol{P}$ Value & Effect Size & Test Power \\
\hline Pre-test & 454.96 & 1 & 454.96 & 217.53 & 0.0001 & 0.73 & 1 \\
Group & 47.84 & 1 & 47.84 & 22.87 & 0.0001 & 0.22 & 0.99 \\
Error level & 161.04 & 77 & 2.09 & & & & \\
Total & 40582.73 & 80 & & & & & \\
\hline
\end{tabular}

Tehran (37). Their findings showed that sexual satisfaction of infertile women was significant three months after counselling. Sexual satisfaction of a woman is her feelings about herself and in relation to physical and sexual aspects and duties, and our study showed that women are able to express their feelings about sexual function (38). This power of expression can be caused by the positive effects of sexual assertiveness counselling. Moreover, considering that one of the most common sexual dysfunctions lies in sexual desire and sexual satisfaction, this counselling approach could reduce such cases. Several studies have shown positive effects of sexual assertiveness on reduction of high risk sexual behaviours and prevention of sexual assaults in women, especially in women who have experienced different cultural conditions or are from different social classes, such as women who feel shame for self-expression or are not able to say "no" (when they do not want to have intercourse) and are forced to meet the sexual desires of their husbands. Additionally, many studies have shown that sexual assertiveness in women can encourage them to be the first person to initiate sex, which in turn would increase their satisfaction and sexuality $(39,40)$.

In our study, scores on the sexual pain component also showed significant changes that were consistent with the study of Vural and Temel (31). However, it is not consistent with findings from Ayaz and Kubilay's study, which investigated the impact of PLISSIT model counselling on sexual function in women with a colostomy (32). This difference could be due to difference in the research population or the different counselling method. Because colostomy pain can be related to sexual pain, today, there are different counselling methods for improving sexual function, and there have been many studies on these methods, such as IMB, PLSSIT, and sex therapy, but so far, no counselling method based on sexual assertiveness and its impact on women's sexual function has been carried out. According to the results of the current study, it was revealed that this method could be an effective way to improve sexual function in women. In other words, this counselling approach was able to influence sexual function and expression of sexual rights and to reduce the shame and contempt that women felt. It is safe to conclude that this method can be used as a way to promote sexuality and to establish a more intimate relationship in marital life, which can ultimately affect the mental health of the family. Although the strong point of this study was that our participants were from different cultures and religions (Shia and Sunni), further studies are necessary in the future to investigate the effectiveness of these interventions for both men and women.

\section{Conclusions}

This research was the first study conducted in Iran on assertiveness-based sexual counselling in the deprived area of Sistan and Baluchestan. Given the religious context of this region, and the shame felt by women in expressing their sexual problems and their inability to take on the role of initiator of sexual relations and that most divorces are due to sexual misunderstanding by the spouse, it is suggested this model be part of a health care plan to reduce divorce rates in Iran.

\section{Limitations and Solutions}

The subjects in this study were married students at the university; therefore, generalization of data should be done with caution. Additionally, loss of subjects and lack of cooperation in presence in consulting sessions were the main constraints of the plan. A multi-stage plan was another limitation. For this reason, reminders of session hours were made in advance by phone calls. If the sample was reduced in each group by more than 1 to 2 people, and in total by more than 5 to 6 people, another intervention group was recruited.

\section{Conflict of Interests}

Authors declare that they have no conflict of interests.

\section{Ethical Issues}

This study was approved by the Ethics Committee of Zahedan University of Medical Sciences, Zahedan, Iran (IR.ZAUMS.REC.1395.244). After obtaining permission from the Ethics Committee, obtaining permission and necessary coordination, and after summarizing the objectives of the study, written informed consent was obtained from all participants.

\section{Financial Support}

The authors received financial support from Zahedan University of Medical Sciences, Zahedan, Iran.

\section{References}

1. Goff JD. The impact of differentiation of self and spirituality on sexual satisfaction. Journal of Psychology and Christianity. 2010;29(1):57-72.

2. Yousefzadeh S, Golmakani N, Nameni F. The Comparison of Sex Education with and without Religious Thoughts in 
Sexual Function of Married Women. J Midwifery Reprod Health. 2017;5(2):904-910. doi:10.22038/jmrh.2017.8384

3. Jahanfar SH, Molaeenezhad M. Text book of sexual disorders 2006. 2nd ed. Tehran: Beezhe Salemi Publication; 2006. [Persian].

4. Rosen R, Brown C, Heiman J, et al. The Female Sexual Function Index (FSFI): a multidimensional selfreport instrument for the assessment of female sexual function. J Sex Marital Ther. 2000;26(2):191-208. doi:10.1080/009262300278597

5. Rafaei Shirpak KH, Chinichian M, Eftekhar Ardebili H, Pourreza AG, Ramezan Khani A. Need assessment: Sexual health education in family planning centers, Tehran, Iran. Payesh. 2010;9(3):251-260.

6. Mohammadi KH, Heydari M, Faghihzadeh S. The female sexual function index (FSFI): validation of the Iranian version . Payesh. 2008;7(3):269-278.

7. Bolourian Z, Ganjloo J. Evaluating sexual dysfunction and some related factors in women attending Sabzevar health care center. J Reprod Infertil. 2007;8(2):163-170.

8. Aslan E, Beji NK, Gungor I, Kadioglu A, Dikencik BK. Prevalence and risk factors for low sexual function in women: a study of 1,009 women in an outpatient clinic of a university hospital in Istanbul. J Sex Med. 2008;5(9):20442052. doi:10.1111/j.1743-6109.2008.00873.x

9. Elnashar AM, El-Dien Ibrahim M, El-Desoky MM, Ali OM, El-Sayd Mohamed Hassan M. Female sexual dysfunction in Lower Egypt. Bjog. 2007;114(2):201-206. doi:10.1111/ j.1471-0528.2006.01106.x

10. Parish WL, Laumann EO, Pan S, Hao Y. Sexual dysfunctions in urban china: a population-based national survey of men and women. J Sex Med. 2007;4(6):1559-1574. doi:10.1111/ j.1743-6109.2007.00596.x

11. Parish WL, Luo Y, Stolzenberg R, Laumann EO, Farrer G, Pan S. Sexual practices and sexual satisfaction: a population based study of Chinese urban adults. Arch Sex Behav. 2007;36(1):5-20. doi:10.1007/s10508-006-9082-y

12. Della Camera PA, Morselli S, Cito G, et al. Sexual health, adherence to Mediterranean diet, body weight, physical activity and mental state: factors correlated to each other. Urologia. 2017;84(4):221-225. doi:10.5301/uj.5000255

13. Laurent SM, Simons AD. Sexual dysfunction in depression and anxiety: conceptualizing sexual dysfunction as part of an internalizing dimension. Clin Psychol Rev. 2009;29(7):573-585. doi:10.1016/j.cpr.2009.06.007

14. Li CC, Rew L, Chen L. Factors affecting sexual function: A comparison between women with gynecological or rectal cancer and healthy controls. Nurs Health Sci. 2014. doi:10.1111/nhs. 12177

15. Vento PW, Cobb RJ. Chronic stress as a moderator of the association between depressive symptoms and marital satisfaction. J Soc Clin Psychol. 2011;30(9):905-936. doi:10.1521/jscp.2011.30.9.905

16. McCabe MP, Goldhammer DL. Demographic and psychological factors related to sexual desire among heterosexual women in a relationship. J Sex Res. 2012;49(1):78-87. doi:10.1080/00224499.2011.569975

17. Pinheiro AP, Raney TJ, Thornton LM, et al. Sexual functioning in women with eating disorders. Int J Eat Disord. 2010;43(2):123-129. doi:10.1002/eat.20671
18. Asadi A, Fathabadi J, Mohammad-Sharifi F. The relationship between marital boredom, Bad believe sexual function and sexual assertiveness in married women. Journal Counseling Psychotherapy Family. 2011;4(3):661-684.

19. Abbassi A, Singh RN. Assertiveness in Marital Relationships Among Asian Indians in the United States. Fam J. 2006;14(4):392-399. doi:10.1177/1066480706290961

20. Matthews SU. Adult attachment styles: relationships with marital and sexual satisfaction. Proquest LLC789 East Eisenhower Parkway, MI,48.106-134.6.2010.

21. Bandura A. Social Cognitive Theory: An Agentic Perspective. Annu Rev Psychol. 2001;52(1):1-26. doi:10.1146/annurev.psych.52.1.1

22. Hargie O, Dickson D, Mallett J, Stringer M. Communicating Social Identity: A Study of Catholics and Protestants in Northern Ireland. Communic Res. 2008;35(6):792-821. doi: $10.1177 / 0093650208324270$

23. Topper M, Emmelkamp PM, Ehring T. Improving prevention of depression and anxiety disorders: Repetitive negative thinking as a promising target. Appl Prev Psychol. 2010;14(1):57-71. doi:10.1016/j.appsy.2012.03.001

24. Bay F. The effect of group therapy feministic on desire and sexual assertiveness among married women [thesis]. Tehran: Tarbiiat Moalem University; 2008.

25. Eunsook L, Heesun K. A study on University Students' Gender Role Stereotype, Sexual Assertiveness, Sexual Assault Recognition, Sexual Violence Permissiveness and Sexual Violence Experience in Dating. J East West Nurs Res. 2014;20(1):48-56. doi:10.14370/jewnr.2014.20.1.48

26. Asadi M, siavoshi H, Shiralipour A, Nazry AM, Miri M, Shayad S. The Relationship between Aggression and Communicational Belief with Sexual Assertiveness on Women. Procedia Soc Behav Sci. 2011;15:922-926. doi:10.1016/j.sbspro.2011.03.213

27. Bahrami N, Alizade S, Bahrami S. The Study of Prevalence of femal sexual dysfunction of childbearing age and related factors. Journal of Scientific Research. 2011;21(75):8-13

28. Fakhri A, Mohammadi-Zeidi I, Pakpour AH , Morshedi H, Mohammad Jafari R, Ghalambor-Dezfooli F. Psychometric Properties of Iranian version of female sexual function Index. Jundishapur Scientific Medical Journal. 2011;10(4):345-354.

29. Vaziri SH, Lotfi-Kashani F, Hoseineian S, Bahram-Ghafari S. Sexual assertiveness and marital satisfaction. Journal Thoughts Behaviour. 2010;4(16):75-81.

30. Brauer M, ter Kuile MM, Laan E. Effects of appraisal of sexual stimuli on sexual arousal in women with and without superficial dyspareunia. Arch Sex Behav. 2009;38(4):476485. doi:10.1007/s10508-008-9371-8

31. Vural BK, Temel AB. Effectiveness of premarital sexual counselling program on sexual satisfaction of recently married couples. Sex Health. 2009;6(3):222-232. doi:10.1071/sh08065

32. Ayaz S, Kubilay G. Effectiveness of the PLISSIT model for solving the sexual problems of patients with stoma. J Clin Nurs. 2009;18(1):89-98. doi:10.1111/j.13652702.2008.02282.x

33. Kiefer AK, Sanchez DT. Scripting sexual passivity: A gender role perspective. Pers Relatsh. 2007;14(2):269-290. doi:10.1111/j.1475-6811.2007.00154.x 
34. Sanchez DT, Phelan JE, Moss-Racusin CA, Good JJ. The Gender Role Motivation Model of women's sexually submissive behavior and Satisfaction in Heterosexual Couples. Pers Soc Psychol Bull. 2012;38(4):528-539. doi:10.1177/0146167211430088

35. Mah K, Binik YM. Are orgasms in the mind or the body? Psychosocial versus physiological correlates of orgasmic pleasure and satisfaction. J Sex Marital Ther. 2005;31(3):187-200. doi:10.1080/00926230590513401

36. Hurlbert DF. The role of assertiveness in female sexuality: A comparative study between sexually assertive and sexually nonassertive women. J Sex Marital Ther. 1991;17(3):183190. doi:10.1080/00926239108404342

37. Pakgohar M, Vizheh M, Babaee G, Ramezanzadeh F,
Abedininia N. Effect of Counseling on Sexual Satisfaction among Infertile Women Referred to Tehran Fertility Center. Hayat. 2008;14(1):21-30.

38. Lamont J. Female sexual health consensus clinical guidelines. J Obstet Gynaecol Can. 2012;34(8):769-775. doi:10.1016/s1701-2163(16)35341-5

39. Santos-Iglesias P, Calvillo G, Sierra JC. A further examination of Levine's model of sexual desire. Psychol Sex. 2013;4(1):34-45. doi:10.1080/19419899.2011.576697

40. Santos-Iglesias P, Vallejo-Medina P, Sierra JC. Equivalence and Standard Scores of the Hurlbert Index of Sexual Assertiveness Across Spanish Men and Women. Anales de psicologia. 2014;30(1):232-237. doi:10.6018/ analesps.30.1.143321

(C) 2018 The Author (s); This is an open-access article distributed under the terms of the Creative Commons Attribution License (http://creativecommons.org/licenses/by/4.0), which permits unrestricted use, distribution, and reproduction in any medium, provided the original work is properly cited. 